\title{
Who's Distressed? A Comparison of Diabetes-Related Distress by Type of Diabetes and Medication
}

\author{
Jana L. Wardian PhD \\ University of Nebraska Medical Center, jana.wardian@unmc.edu \\ Joshua Tate \\ San Antonio Military Medical Center \\ Irene Folaron \\ San Antonio Military Medical Center \\ Sky Graybill \\ San Antonio Military Medical Center \\ Mark True \\ San Antonio Military Medical Center
}

See next page for additional authors

Tell us how you used this information in this short survey.

Follow this and additional works at: https://digitalcommons.unmc.edu/com_hosp_articles

\section{Recommended Citation}

Wardian, Jana L. PhD; Tate, Joshua; Folaron, Irene; Graybill, Sky; True, Mark; and Sauerwein, Tom, "Who's Distressed? A Comparison of Diabetes-Related Distress by Type of Diabetes and Medication" (2018). Journal Articles: Hospital Medicine. 14.

https://digitalcommons.unmc.edu/com_hosp_articles/14

This Article is brought to you for free and open access by the Hospital Medicine at DigitalCommons@UNMC. It has been accepted for inclusion in Journal Articles: Hospital Medicine by an authorized administrator of DigitalCommons@UNMC.For more information, please contact digitalcommons@unmc.edu. 


\section{Authors}

Jana L. Wardian PhD, Joshua Tate, Irene Folaron, Sky Graybill, Mark True, and Tom Sauerwein 


\title{
Who's distressed? A comparison of diabetes-related distress by type of diabetes and medication
}

\author{
Jana L. Wardian ${ }^{\mathrm{a}, *}$, Joshua Tate ${ }^{\mathrm{b}}$, Irene Folaron ${ }^{\mathrm{b}}$, Sky Graybill ${ }^{\mathrm{b}}$, Mark True ${ }^{\mathrm{b}}$, \\ Tom Sauerwein ${ }^{a}$ \\ a Diabetes Center of Excellence, Wilford Hall Ambulatory Surgical Center, Joint Base San Antonio, Lackland, TX 78236, United States \\ ${ }^{\mathrm{b}}$ Endocrinology Service, San Antonio Military Medical Center, Joint Base San Antonio, Ft. Sam Houston, TX 78234, United States
}

\section{A R T I C L E I N F O}

\section{Article history:}

Received 6 June 2017

Received in revised form 26 February 2018

Accepted 1 March 2018

\section{Keywords:}

Diabetes-related distress

Regimen distress

Emotional burden

Type 1 diabetes

Type 2 diabetes

\begin{abstract}
A B S T R A C T
Objective: We hypothesized that diabetes-related distress would vary by type of diabetes and medication regimen [Type 1 diabetes (T1DM), Type 2 diabetes with insulin use (T2DM-i), Type 2 diabetes without insulin use (T2DM)]. Thus, the aim of this study was to identify groups with elevated diabetes-related distress.

Methods: We administered the 17-item Diabetes-related Distress Scale (DDS-17) to 585 patients. We collected demographics, medications, and lab results from patient records.

Results: Patients were categorized by type of diabetes and medication: T1DM ( $\mathrm{n}=149)$; T2DM-i $(n=333)$; and T2DM $(n=103)$. ANOVA revealed significant differences in sample characteristics. ANCOVA were conducted on all four DDS-17 domains [Emotional Burden (EB); Physician-related Distress (PD); Regimen-related Distress (RD); and Interpersonal Distress (ID)]; covariates included in the models were sex, age, duration of diabetes, BMI, and HbA1c. EB was significantly lower in T1DM than T2DM-i, $p<0.05$. In addition, RD was significantly lower in T1DM than either T2DM-i, $p<0.05$ and T2DM, $p<0.05$. Conclusions: EB and RD are higher for those with type 2 diabetes. Thus, interventions to reduce EB and RD need to be considered for patients with type 2 diabetes.

Implications: DDS-17 is useful in identifying diabetes-related distress in patients with diabetes. Efforts need to be made to reduce EB and RD.
\end{abstract}

Published by Elsevier B.V.
Managing diabetes is not easy. Polonsky and associates describe diabetes as a "complex, demanding, and often confusing set of selfcare directives" in which "patients may become frustrated, angry, overwhelmed, and/or discouraged" (p. 626) [1]. Accordingly, the American Diabetes Association (ADA) position statement recommends psychosocial assessment as an integrated part of routine care for people with diabetes (Young-Hyman, 2016) [2].

The concept of diabetes-related distress, which encompasses patients' concerns about self-care, support, emotional burden, and quality of healthcare, is a common challenge for people with

Abbreviations: ADA, American Diabetes Association; ANOVA, analysis of variance; DoD, Department of Defense; DCOE, Diabetes Center of Excellence; DDS-17, Diabetes-related Distress Scale; EB, emotional burden; ID, interpersonal distress; PD, physician-related distress; RD, regimen-related distress; T1DM, type 1 diabetes; T2DM-i, type 2 diabetes with insulin use; T2DM, type 2 diabetes without insulin use.

* Corresponding author at: Diabetes Center of Excellence, Wilford Hall Ambulatory Surgical Center, 1100 Wilford Hall Loop, JBSA Lackland AFB, TX 78236, United States. Phone:. +(210) 292-5037 Fax: +(210)-292-4915.

E-mail address: Jana.L.Wardian.ctr@mail.mil (J.L. Wardian). diabetes [1,3]. While depression is prevalent in people with diabetes, diabetes-related distress has been found to be even more common, with a prevalence of $18-35 \%$ [4,5]. Diabetes-related distress is noted to be a separate clinical entity, whereby about 70\% of patients with identified diabetes-related distress were not clinically depressed [4,6]. Diabetes-related distress can be assessed using the 17-item Diabetes-related Distress Scale (DDS-17), which measures diabetes-related distress in four distinct domains: 1) emotional burden (EB); 2) physician-related distress (PD); 3) regimen-related distress (RD); and 4) interpersonal distress (ID) [1-3]. These domains are further described in Table 1.

Elevated diabetes-related distress is related to poorer selfmanagement, worse medication adherence, and lower quality of life $[7,8]$. Moreover, greater HbA1c values correlate with higher diabetes-related distress [5,8]; conversely, lower diabetes-related distress levels are associated with patient self-efficacy and physician support [9]. In addition, higher DDS-17 scores were associated with women, younger patients, and those with higher BMI [9]. For patients with T1DM, diabetes-related distress has been experienced somewhat differently than for patients with T2DM 
Table 1

The 17-item Diabetes-related Distress Scale (DDS-17).

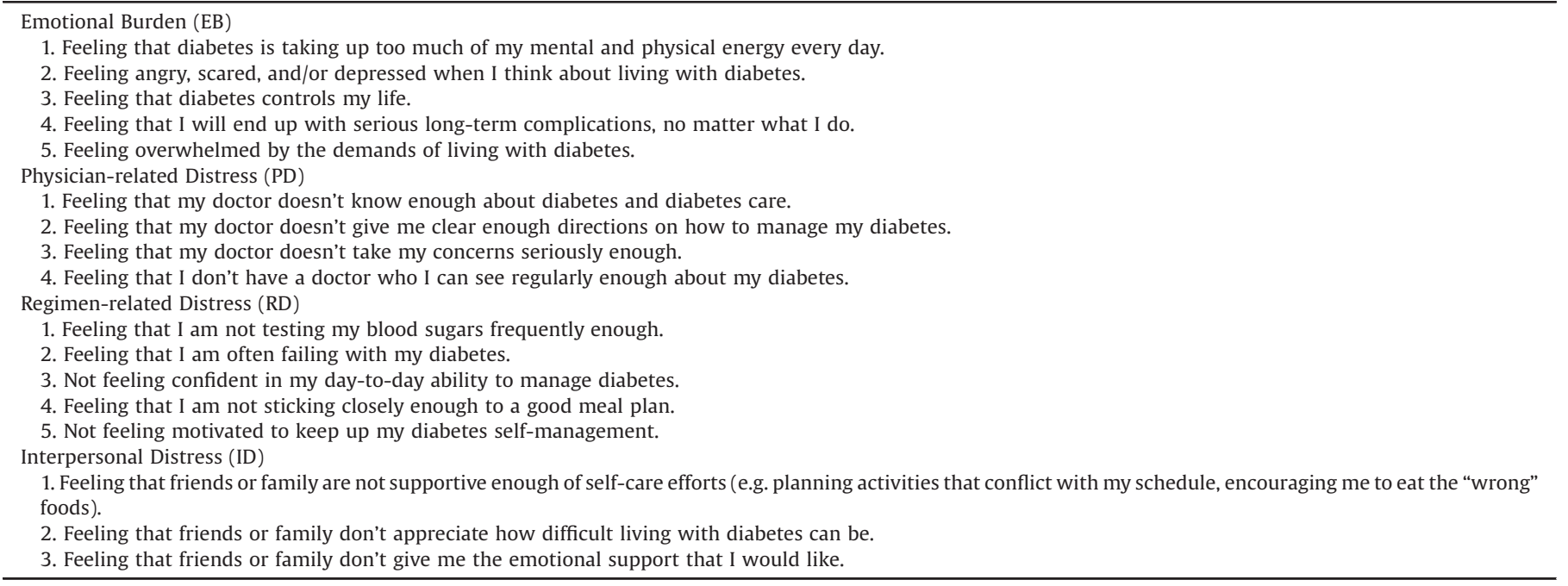

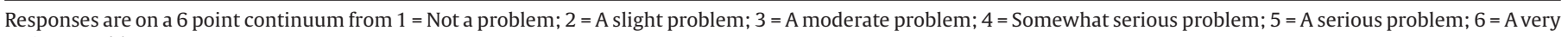
serious problem.

[10]. EB originates predominantly from a sense of powerlessness, reflecting ongoing frustrations with managing glucose when much of the variation is outside of their control [10]. RD also comes from concerns about not monitoring blood glucose enough, fears that eating constraints are controlling their life, and a more pronounced fear of hypoglycemia [10]. To a lesser extent, patients with T1DM have interpersonal and physician-related distress.

Despite knowing the relationship of diabetes-related distress to diabetes-related health outcomes, the relationship to type of diabetes and medication regimen has not been evaluated.

This study sought to explore these factors as they relate to high diabetes-related distress measured by DDS-17 in a diabetes clinic setting. We hypothesized that DDS-17 would significantly vary by type of diabetes and medication regimen [Type 1 diabetes (T1DM), Type 2 diabetes with insulin use (T2DM-i), Type 2 diabetes without insulin use (T2DM)]. The goal of our study was to identify groups with elevated diabetes-related distress, which would enable a targeted intervention to decrease diabetes-related distress in the specific domain.

\section{Research design and methods}

Wilford Hall Ambulatory Surgical Center Institutional Review Board approval was obtained for this retrospective data analysis. Data were collected at the Diabetes Center of Excellence (DCOE) through chart reviews of clinical visits from June 2015 through August 2016. The DCOE is an Air Force diabetes specialty clinic treating challenging cases of diabetes including patients with type 1 diabetes (T1DM) and patients with complex diabetes. Our patient population consists of all branches of active duty military, retired, and family members. The DCOE began administering the 17-item Diabetes-related Distress Scale (DDS-17) in June 2015 as standard

Diabetes Distress Scale

\begin{tabular}{|c|c|c|c|c|}
\hline \multicolumn{2}{|c|}{ Question } & \multirow{2}{*}{\multicolumn{2}{|c|}{ Total DDS }} & \multirow{3}{*}{ PRIOR DDS } \\
\hline 1 & 1 & & & \\
\hline 2 & 4 & \multirow{4}{*}{\multicolumn{3}{|c|}{ Emotional Burden }} \\
\hline 3 & 3 & & & \\
\hline 4 & 2 & & & \\
\hline 5 & 1 & & & \\
\hline 6 & 4 & \multirow{2}{*}{\multicolumn{2}{|c|}{ ○ 3.4}} & \\
\hline 7 & 3 & & & \\
\hline 8 & 5 & \multicolumn{3}{|c|}{ Physician-related Distress } \\
\hline 9 & 1 & 0 & 2 & \\
\hline 10 & 2 & \multirow{2}{*}{\multicolumn{3}{|c|}{ Regimen-related Distress }} \\
\hline 11 & 4 & & & \\
\hline 12 & 4 & 0 & 3 & \\
\hline 13 & 2 & \multirow{2}{*}{\multicolumn{3}{|c|}{ Interpersonal Distress }} \\
\hline 14 & 4 & & & \\
\hline 15 & 1 & \multirow[t]{3}{*}{$\mathrm{O}$} & 2.7 & \\
\hline 16 & 4 & & & \\
\hline 17 & 3 & & & \\
\hline
\end{tabular}

Fig. 1. "DDS-17 Dashboard in the NoteWriter". 
care (Table 1 ). Responses were on a 6 point continuum from $1=$ Not a problem; $2=\mathrm{A}$ slight problem; $3=\mathrm{A}$ moderate problem; 4 = Somewhat serious problem; $5=$ A serious problem; $6=$ A very serious problem. DDS-17 domains were calculated as a sum of the total and divided by the number of items in each domain: EB ( 5 items); PD (4 items); RD (5 items); and ID (3 items). It should be noted that Fenwick et al. [11] suggest that total DDS-17 score should be avoided; thus discussion of the four individual domains will be presented.

Inclusion criteria were adult patients (19 and older) with diabetes receiving their diabetes care at the DCOE. Data were stored on military computers that were password and firewall protected. As part of the regular patient visit, all patients completed the DDS-17 and responses were recorded by licensed vocational nurses. All patients completed a DDS-17 as part of the clinical visit $(\mathrm{N}=585)$.

After input, the NoteWriter, an Excel-based clinical note writing platform, calculated scores for total DDS and each subscale. Fig. 1 shows the NoteWriter, DDS-17 total and subscale scores with associated level of distress designated by a color-coded radial button on the dashboard: green indicated $<2.0=$ little or no diabetes-related distress; yellow indicated 2.0-2.9 or moderate diabetes-related distress; or red $>3.0$ signaled high diabetesrelated distress, which are consistent with cut points established by Fisher et al. [12]. The area(s) designated as yellow or red were further explored by the provider to determine the source of the diabetes-related distress and collaborate with the patient to determine strategies to reduce the associated distress.

In addition to the DDS-17, data included patient demographics (gender, age, ethnicity/race, rank, military status) and lab results (comprehensive metabolic panel including HbA1c).

Analyses were conducted using SPSS version 22. Univariate analyses were conducted to characterize the sample. Type of diabetes and medication regimen were used to transform data into three distinct groups (T1DM, T2DM-i, and T2DM). One-way analysis of variance (ANOVA) were conducted to assess differences in means between and among groups on sample characteristics. This was followed by Analysis of Covariance (ANCOVA) to control for significantly different sample characteristics when examining the four domains of DDS-17 among the three groups.

\section{Results}

A total of 610 DCOE patients completed a baseline DDS-17 from June 2015 through August 2016. However, 25 patients were categorized as "other" type of diabetes, which left 585 patients that could be categorized.

One-way ANOVA was conducted to detect significant differences among and between groups on demographic and clinical markers (Table 2). There were slightly more men than women represented in the data with significant variation between the T1DM group and the T2DM-i group according to sex. Patients with T1DM were significantly younger (46.0 years) than the other groups. As expected, T1DM patients were significantly younger at diagnosis (26.5 years) compared to the Type 2 diabetes groups. Duration of diabetes was significantly higher in T1DM (20.1 years) followed by T2DM-i (16.9 years) and T2DM (9.1 years). Overall, $43.3 \%$ of the sample were White; $21.6 \%$ were African American; and 27.5\% Hispanic/Latino. Those in the T1DM category were mostly White (63.5\%); this was significantly higher when compared to each of the Type 2 diabetes groups. There was no significant difference in African Americans among the three groups; however, Hispanics were significantly lower in the T1DM group compared to each of the Type 2 diabetes groups.

Military rank included both active duty and retired members and was evenly distributed within the T1DM category, but in the T2DM-i and T2DM groups, senior enlisted were significantly higher and represented about $40 \%$ of the sample. Family members accounted for about $66 \%$ of the T1DM group and about $40 \%$ of the Type 2 DM groups.

Clinical measures included BMI and HbA1c. Both were lowest in the T1DM group, followed by the T2DM group and highest in T2DM-i patients; this was significantly different between the T1DM group and each of the Type 2 diabetes groups.

The four DDS-17 subscales were subjected to analysis of covariance (ANCOVA) to examine differences in means between

Table 2

Sample Characteristics by Type of Diabetes and Medication Regimen Compared across Groups.

\begin{tabular}{|c|c|c|c|c|c|c|c|}
\hline & \multicolumn{2}{|l|}{ T1DM } & \multicolumn{2}{|l|}{ T2DMi } & \multicolumn{2}{|l|}{$\mathrm{T} 2 \mathrm{DM}$} & \multirow[b]{2}{*}{ P value } \\
\hline & $\begin{array}{l}\mathrm{n} \\
149\end{array}$ & $\begin{array}{l}\% \\
25.5 \%\end{array}$ & $\begin{array}{l}\mathrm{n} \\
333\end{array}$ & $\begin{array}{l}\text { \% } \\
56.9 \%\end{array}$ & $\begin{array}{l}\mathrm{n} \\
103\end{array}$ & $\begin{array}{l}\% \\
17.6 \%\end{array}$ & \\
\hline \multicolumn{8}{|l|}{ Sex } \\
\hline Female & 82 & $55.0 \%^{\mathrm{a}}$ & 141 & $42.3 \%^{\mathrm{a}}$ & 43 & $41.7 \%$ & $<\mathbf{0 . 0 5}$ \\
\hline Male & 67 & $45.0 \%$ & 192 & $57.7 \%$ & 60 & $58.3 \%$ & \\
\hline Mean Age & $46.0^{c}$ & - & $59.9^{c}$ & - & $53.3^{c}$ & - & $<\mathbf{0 . 0 5}$ \\
\hline Age at Diagnosis & $26.5^{\mathrm{a}, \mathrm{b}}$ & - & $43.2^{\mathrm{a}}$ & - & $45.6^{\mathrm{b}}$ & - & $<\mathbf{0 . 0 5}$ \\
\hline Duration of Diabetes & $20.1^{\mathrm{c}}$ & - & $16.9^{\mathrm{c}}$ & - & $9.1^{\mathrm{c}}$ & - & $<\mathbf{0 . 0 5}$ \\
\hline \multicolumn{8}{|l|}{ Ethnicity/Race } \\
\hline White & 94 & $63.5 \%$ a,b & 127 & $38.4 \%^{\mathrm{a}}$ & 31 & $30.1 \% \mathrm{~b}$ & $<0.05$ \\
\hline African American & 30 & $20.3 \%$ & 73 & $22.1 \%$ & 23 & $22.3 \%$ & NS \\
\hline Hispanic/Latino & 16 & $10.8 \%{ }^{\mathrm{ab}}$ & 106 & $32.0 \%^{\mathrm{a}}$ & 38 & $36.9 \%^{\mathrm{b}}$ & $<\mathbf{0 . 0 5}$ \\
\hline \multicolumn{8}{|l|}{ Military Rank } \\
\hline Junior Enlisted & 15 & $30.6 \%{ }^{\mathrm{a}}$ & 76 & $39.8 \%^{\mathrm{a}}$ & 22 & $38.6 \%$ & $<0.05$ \\
\hline Senior Enlisted & 17 & $34.7 \%{ }^{\mathrm{a}, \mathrm{b}}$ & 89 & $46.6 \%^{\mathrm{a}}$ & 27 & $47.4 \%$ & $<\mathbf{0 . 0 5}$ \\
\hline Officer & 17 & $34.7 \%$ & 26 & $13.6 \%$ & 8 & $14.0 \%$ & NS \\
\hline \multicolumn{8}{|l|}{ Military Status } \\
\hline Active Duty & 14 & $9.6 \%^{\mathrm{a}}$ & 10 & $3.0 \%$ & 10 & $9.7 \%$ & $<0.05$ \\
\hline Retired & 36 & $24.7 \%^{\mathrm{a}, \mathrm{b}}$ & 182 & $55.3 \%^{\mathrm{a}}$ & 48 & $46.6 \%^{\mathrm{b}}$ & $<\mathbf{0 . 0 5}$ \\
\hline Family Member & 96 & $65.8 \%$ & 137 & $41.6 \%^{\mathrm{a}}$ & 45 & $43.7 \%^{\mathrm{b}}$ & $<0.05$ \\
\hline BMI & $28.48^{\mathrm{c}}$ & - & $33.86^{\mathrm{c}}$ & - & $31.15^{\mathrm{c}}$ & - & $<\mathbf{0 . 0 5}$ \\
\hline Current HbA1c & $8.00 \%$ & - & $8.38 \%$ & - & $8.30 \%$ & - & NS \\
\hline
\end{tabular}

NS = No Significance.

T1DM = Type 1 diabetes; T2DM-i = Type 2 diabetes on insulin therapy; T2DM = Type 2 diabetes not on insulin therapy .

a Significant difference between these 2 variables $(<0.05)$.

b Significant difference between these 2 variables $(<0.05)$.

c Significant difference among all 3 variables $(<0.05)$. 
and among groups when controlling for covariates (age, sex, duration of diabetes, BMI, and HbA1c) and applying a Bonferroni correction to adjust for multiple comparisons (Table 3). Levene's test was conducted for all models, normality checks were carried out and assumptions were met.

After controlling for covariates, those with T1DM had significantly lower EB than those with T2DM-i, $F(7,547)=11.715$, $p<0.001$, partial $n^{2}=0.026$. The covariates of younger age $(\beta=-0.018$; $S E=0.004, p<0.001)$ and higher HbA1c $(\beta=0.171$; $\mathrm{SE}=0.03, \mathrm{p}<0.001)$ were associated with higher $\mathrm{EB}$. This model explains $11.9 \%$ of the variance in $\mathrm{EB}$.

After controlling for covariates, the overall model for PD was not significant for differences among or between groups, $F(2$, $547)=1.730, p=0.178$, partial $n^{2}=0.006$. However, younger age $(\beta=-0.006 ; \mathrm{SE}=0.003, p=0.03)$ and higher HbA1c $(\beta=0.056$; $\mathrm{SE}=0.02, \mathrm{p}=0.002$ ) were associated with higher PD. This model explains $2.8 \%$ of the variance in $\mathrm{PD}$.

After adjusting for covariates, those with T1DM had significantly lower RD than T2DM-i and T2DM, $F(2,547)=5.291$, $p=0.005$, partial $n^{2}=0.019$. Significant differences were found between T1DM and T2DM-i groups $(p=0.005)$ and T1DM and T2DM groups $(p=0.033)$. Covariates of younger age $(\beta=-0.016$; $\mathrm{SE}=0.004, \mathrm{p}<0.001)$, female sex $(\beta=0.237 ; \mathrm{SE}=0.08, \mathrm{p}=0.005)$, higher BMI $(\beta=0.014 ; \mathrm{SE}=0.01, p=0.02)$, and higher HbA1c $(\beta=0.184 ; \mathrm{SE}=0.03, \mathrm{p}<0.001)$ were associated with higher $\mathrm{RD}$. This model explains $15.6 \%$ of variance in $\mathrm{RD}$.

Table 3

ANCOVA on DDS-17 Domains by Type of Diabetes and Medication Regimen.

\begin{tabular}{|c|c|c|c|c|c|c|c|}
\hline & \multicolumn{2}{|c|}{ T1DM } & \multicolumn{2}{|c|}{ T2DM-i } & \multicolumn{2}{|c|}{ T2DM } & \multirow{3}{*}{$\begin{array}{l}\text { ANCOVA } \\
\text { p value }\end{array}$} \\
\hline & $\mathrm{n}$ & $\%$ & $\mathrm{n}$ & $\%$ & $\mathrm{n}$ & & \\
\hline & 149 & $25.5 \%$ & 333 & $56.9 \%$ & 103 & $17.6 \%$ & \\
\hline \multicolumn{8}{|c|}{ Emotional Burden (EB) } \\
\hline Low & 96 & $64.4 \%$ & 182 & $54.7 \%$ & 62 & $60.2 \%$ & \\
\hline Moderate & 30 & $20.1 \%$ & 84 & $25.2 \%$ & 29 & $28.2 \%$ & \\
\hline High & 23 & $15.4 \%$ & 67 & $20.1 \%$ & 12 & $11.7 \%$ & \\
\hline $\mathbf{M}(\mathbf{S D})$ & \multicolumn{2}{|c|}{$1.868(0.99)$} & \multicolumn{2}{|c|}{$2.108(1.15)$} & \multicolumn{2}{|c|}{$1.874(0.93)$} & \\
\hline Adjusted M(SE) & \multicolumn{2}{|c|}{$1.694(0.10)^{\mathrm{a}}$} & \multirow{2}{*}{\multicolumn{2}{|c|}{$\begin{array}{l}2.166(0.06)^{a} \\
(2.05 ; 2.29)\end{array}$}} & \multirow{2}{*}{\multicolumn{2}{|c|}{$\begin{array}{l}1.951(0.11) \\
(1.73 ; 2.17)\end{array}$}} & $<\mathbf{0 . 0 5}$ \\
\hline $95 \% \mathrm{CI}$ & $(1.50$ & 1.89) & & & & & \\
\hline \multicolumn{8}{|c|}{ Physician-related Distress (PD) } \\
\hline Low & 140 & $94.0 \%$ & 301 & $90.7 \%$ & 90 & $87.4 \%$ & \\
\hline Moderate & 6 & $4.0 \%$ & 15 & $4.5 \%$ & 6 & $5.8 \%$ & \\
\hline High & 3 & $2.0 \%$ & 16 & $4.8 \%$ & 7 & $6.8 \%$ & \\
\hline M(SD) & \multicolumn{2}{|c|}{$1.171(0.51)$} & \multicolumn{2}{|c|}{$1.261(0.76)$} & \multicolumn{2}{|c|}{$1.320(0.69)$} & \\
\hline Adjusted M(SE) & \multicolumn{2}{|c|}{$1.149(0.07)$} & \multicolumn{2}{|c|}{$1.265(0.04)$} & \multicolumn{2}{|c|}{$1.341(0.08)$} & NS \\
\hline $95 \% \mathrm{CI}$ & \multicolumn{2}{|c|}{$1.02,1.28$} & \multicolumn{2}{|c|}{$1.19,1.35$} & \multicolumn{2}{|c|}{$1.19,1.49$} & \\
\hline \multicolumn{8}{|c|}{ Regimen-related Distress (RD) } \\
\hline Low & 98 & $65.8 \%$ & 177 & $53.2 \%$ & 59 & $57.3 \%$ & \\
\hline Moderate & 35 & $23.5 \%$ & 91 & $27.3 \%$ & 25 & $24.3 \%$ & \\
\hline High & 16 & $10.7 \%$ & 65 & $19.5 \%$ & 19 & $18.4 \%$ & \\
\hline $\mathbf{M}(\mathbf{S D})$ & \multicolumn{2}{|c|}{$1.859(0.96)$} & \multicolumn{2}{|c|}{$2.137(1.06)$} & \multicolumn{2}{|c|}{$2.113(1.04)$} & \\
\hline Adjusted M(SE) & \multicolumn{2}{|c|}{$1.786(0.09)^{a, b}$} & \multicolumn{2}{|c|}{$2.159(0.06)^{a}$} & \multicolumn{2}{|c|}{$2.156(0.11)^{b}$} & $<\mathbf{0 . 0 5}$ \\
\hline $95 \% \mathrm{CI}$ & \multicolumn{2}{|c|}{$1.60,1.97$} & \multicolumn{2}{|c|}{$2.05,2.27$} & 1.95 & 2.37 & \\
\hline Interpersonal Dis & ress ( & & & & & & \\
\hline Low & 123 & $82.6 \%$ & 259 & $77.8 \%$ & 89 & $86.4 \%$ & \\
\hline Moderate & 14 & $9.4 \%$ & 46 & $13.8 \%$ & 8 & $7.8 \%$ & \\
\hline High & 12 & $8.1 \%$ & 28 & $8.4 \%$ & 6 & $5.8 \%$ & \\
\hline $\mathrm{M}(\mathrm{SD})$ & 1.141 & $(0.85)$ & 1.50 & $(0.89)$ & 1.37 & $(0.80)$ & \\
\hline Adjusted M(SE) & 1.39 & $0.08)$ & 1.49 & $(0.05)$ & 1.42 & $(0.10)$ & NS \\
\hline 95\% CI & 1.23 & .56 & 1.40 , & 1.60 & 1.24 & 1.61 & \\
\hline
\end{tabular}

T1DM = Type 1 diabetes; T2DM-i = Type 2 diabetes on insulin therapy; T2DM = Type 2 diabetes not on insulin therapy.

Cut points for DDS-17 domains were established by Fisher et al. (2012) and include

$<2.0=$ little or no distress; $2.0-2.9=$ moderate diabetes-related distress; $\geq 3=$ high diabetes-related distress.

Models were adjusted for age, sex, duration of diabetes, BMI, and HbA1c.

NS = No Significance

a Significant difference between these 2 variables $(<0.05)$

b Significant difference between these 2 variables $(<0.05)$.
ID was not significantly different among groups, $F(2$, $547)=0.0573, p=0.56$, partial $n^{2}=0.002$. However, covariates of female sex $(\beta=0.221 ; \mathrm{SE}=0.37, \mathrm{p}=0.003)$ and higher $\mathrm{HbA} 1 \mathrm{c}$ $(\beta=0.084 ; \mathrm{SE}=0.02, \mathrm{p}<0.001)$ were significantly associated with higher ID. This model explains $4.0 \%$ of variance in ID.

\section{Discussion}

Our results demonstrate that $\mathrm{EB}$ and $\mathrm{RD}$ were experienced differently in our patients by type of diabetes and medication regimen; however, PD and ID were not significantly different among the three groups. Patients in either T2DM-i or T2DM reported significantly higher RD compared with T1DM. Only T2DM-i patients were significantly more likely to experience EB than patients with T1DM. Identifying EB and RD as the predominant sources of diabetes-related distress enables targeted interventions and modifications in our patient-centered encounters to reduce these sources of distress.

Self-care requirements, perception of higher disease severity, physical discomfort of injections, fear of hypoglycemia, and anxiety related to other complications are cited as unique sources of EB for patients taking insulin [13,14]. Even the thought of insulin has been associated with high EB for those who do not yet require insulin. Many patients view insulin as a sign of failure in self-care and a forecast of reduced flexibility in life $[15,16]$. The negative appraisal of insulin and the resulting high EB are important insights for the provider. How insulin therapy is presented must be considered when designing diabetes education and engaging in shared decision-making towards meaningful clinical goals.

Those with high EB, whether or not they were already on insulin, were found to have negative appraisals of insulin therapy [17]. For the T2DM group not on insulin, EB was the second leading cause of diabetes-related distress after RD. Since the DCOE is a diabetes specialty clinic and cares for patients with more complex diabetes, our patients with T2DM may experience increased anxiety about the possibility of initiating insulin therapy if their diabetes cannot be effectively managed on non-insulin medications. People with diabetes are often anxious about initiating insulin therapy $[17,18]$ and providers may help alleviate reluctance by discussing and addressing beliefs about insulin therapy. Furthermore, there is evidence that elevated EB may be associated with a sense of powerlessness with managing diabetes; many factors related to optimal blood sugar management are not within the control of the patient [10].

Insulin therapy is one factor in EB, but $E B$ is a more comprehensive construct.

In totality, other forms of diabetes-related distress feed into a patient's EB. For example, a survey study among ethnically diverse patients with T2DM found that culturally competent communication and trust in their physicians, a factor in PD, were associated with lower EB $[18,19]$. Additionally, the perception of low social support, a factor in ID, was associated with higher EB [20]. Our population reported relatively low levels of PD and ID. Therefore, our results would suggest that high EB in our population may be attributed to the insulin requirement. However, to avoid over simplification, future studies should explore other factors that may be related to elevated $\mathrm{EB}$.

An interesting finding in this study is that people with T2DM-i and T2DM were significantly more likely to have RD than people with T1DM. People with T1DM require insulin upon diagnosis, but many people with type 2 diabetes manage diabetes with lifestyle adjustments and/or non-insulin regimens for a period of time [21], which may make adding insulin therapy more complex by comparison. Patients with type 2 diabetes may additionally experience a sense of guilt that they are responsible for the 
disease progression, which may be compounded by a sense of failure if they require insulin [10,22,23].

Furthermore, people with type 2 diabetes often have cooccurring conditions (ie hypertension, dyslipidemia, cardiovascular disease), which require additional medications [21]. Logically, patients are more adherent to simple medication regimens compared to complex ones; thus, a reasonable conclusion is that simpler medication regimens would induce less RD. However, this over simplifies RD; medication dosing is only one factor than can contribute to RD. All patients with diabetes share challenges with multifaceted management regimens, which include blood sugar monitoring, timing of medication with meals, and concerns about extremes in blood sugar as a consequence of intentional or unintentional non-adherence to any aspect of the regimen.

Overall, in our patient population, PD contributed the least to diabetes-related distress, as about $90.7 \%$ had low PD. We attribute this finding to several causes. Primarily, we conducted the study at the DCOE, a specialty center where patients receive care from endocrinologists or from providers who are closely supervised by endocrinologists. A patient is less likely to have a concern about a provider's diabetes knowledge in our center as compared to a primary care clinic.

Additionally, the DCOE embraces a multidisciplinary approach to each patient encounter such that several individuals interact with the patient [25]. Before the visit, medical assistants review the patient record to identify any issues or upcoming deadlines to meet diabetes standard of care. During the visit, they also perform a structured patient intake, medication reconciliation, and perform foot examinations when due. These actions enable providers to be more focused on patient concerns and treatment plans during their portion of the encounter. Certified diabetes educators are available after the provider visit to reinforce the plan and perform additional teaching regarding how to use new equipment (e.g., insulin pens, continuous glucose monitors, insulin pumps, etc.).

A patient-centered approach is central to the DCOE philosophy. The concepts of motivational interviewing and shared-decision making are discussed, reviewed, and taught by staff on a regular basis. It is, therefore, very unusual for a patient to voice a complaint that his or her concerns are unheard or not taken seriously. Finally, the DCOE support staff members make themselves available to patients between provider visits by inviting phone calls to the clinic, communication via the secure messaging system, or additional Certified Diabetes Educator encounters as needed to address issues. Concerns that cannot be addressed by support staff are elevated to providers.

A significant negative correlation between social support satisfaction and ID has been described with number of supports and support satisfaction significantly moderating the relationship between diabetes burden and ID [26]. Lower ID was seen with higher levels of social support, including an increase in number of individuals available to provide support [26]. Furthermore, social support was associated with improved clinical outcomes and improved adaptation of beneficial lifestyle activities [26,27]. ID in our population was low among all groups and without statistical difference among the groups. This may be attributable to the fact that military members, retirees, and their families represent a unique subset of the population with access to established family support programs and resource centers created by the military to help improve support structures [28]. Lower divorce rates compared to the civilian sector may be another area that explains lower ID through increased social support, as cohabitation/marital status has been shown to have better diabetes-related outcomes and lower diabetes-related distress with increased social support as the explanatory factor $[29,30]$.

\section{Limitations}

Several limitations must be noted due to our distinctive population and generalizability must be done with caution. Application of the DDS-17 in a different population yielded opposite results with higher PD and ID in those with T2DM, underscoring the heterogeneity in the spectrum of patient distress [8]. The DCOE is an Air Force diabetes specialty clinic, which exclusively treats Department of Defense (DoD) beneficiaries [25]. Thus, access to healthcare differs from a civilian population. Notably, there is no cost for healthcare including visits, medication, and blood sugar monitoring supplies. This may influence diabetesrelated distress in a number of ways. One could argue that this benefit would reduce DDS-17 across all domains; however, along with essentially free healthcare comes limited choice in providers and reduced options, as some medications are not included on the formulary. In addition, some of our patients travel long distances to receive care at the DCOE, which could be an additional stressor.

Future studies may want to examine the role of disease severity in diabetes-related distress including co-morbidities and diabetesrelated complications. In addition, examining the contribution of various indicators of disease severity including length of diagnosis, HbA1c, number and type of medication(s), and complications associated with diabetes.

\section{Practice implications}

Providers benefit from an awareness of the differences in diabetes-related distress experienced by patients according to the type of diabetes and their medication regimen. Since insulin therapy is associated with higher RD and EB, intentional efforts must be made to assist patients in understanding that diabetes is a progressive condition. Insulin therapy may become necessary over time even if the person with diabetes has been able to manage diabetes well on non-insulin therapies.

Furthermore, providers may inadvertently be contributing to patient distress when they suggest the patient should be able to "control" diabetes [24]. Instead, empowering patients to learn skills and strategies to better manage diabetes is necessary. Certified diabetes educators can be invaluable in assessing current skills, improving problem solving, and teaching techniques to reduce pain of injections or finger sticks.

Employing an interdisciplinary approach to caring for patients experiencing elevated diabetes-related distress is optimal. This may include a PharmD who can reconcile medications and suggest alternative combo medications. It may also include a mental healthcare professional who can assist with ID, use therapeutic approaches designed to lower anxiety or reduce intrusive thoughts.

\section{Conclusion}

Diabetes-related distress is an important psychosocial aspect of care for people with diabetes. Assessing diabetes-related distress on a regular basis is consistent with standards of diabetes care [21]. Understanding who may be experiencing diabetes-related distress and where the source of the distress is located assists providers in tailoring interventions to reduce diabetes-related distress; thus, enabling patients to better engage in self-management and reach their treatment goals.

\section{Acknowledgements}

The views expressed in this article are those of the authors and do not reflect the official policy or position of the U.S. Air Force, Department of Defense, or its components. 
This study was accepted for a poster presentation at the 2017 American Diabetes Association annual meeting in San Diego, CA, June 9-13, 2017.

There is no funding for this study. The authors have no conflicts of interest to disclose.

\section{References}

[1] W.H. Polonsky, L. Fisher, J. Earles, R.J. Dudl, J. Lees, J. Mullan, R.A. Jackson, Assessing psychosocial distress in diabetes development of the diabetes distress scale, Diabetes Care 28 (3) (2005) 626-631.

[2] D. Young-Hyman, M. de Groot, F. Hill-Briggs, J.S. Gonzalez, K. Hood, M. Peyrot, Psychosocial care for people with diabetes: a position statement of the American Diabetes Association, Diabetes Care 39 (12) (2016) 2126-2140.

[3] L. Fisher, M.M. Skaff, J.T. Mullan, P. Arean, R. Glasgow, U. Masharani, A longitudinal study of affective and anxiety disorders, depressive affect and diabetes distress in adults with type 2 diabetes, Diabet. Med. 25 (9) (2008) 1096-1101.

[4] L. Fisher, M.M. Skaff, J.T. Mullan, P. Arean, D. Mohr, U. Masharani, G. Laurencin, et al., Clinical depression versus distress among patients with type 2 diabetes, Diabetes Care 30 (3) (2007) 542-548.

[5] L. Fisher, J.T. Mullan, P. Arean, R.E. Glasgow, D. Hessler, U. Masharani, Diabetes distress but not clinical depression or depressive symptoms is associated with glycemic control in both cross-sectional and longitudinal analyses, Diabetes Care 33 (1) (2010) 23-28.

[6] L. Fisher, J.T. Mullan, M.M. Skaff, R.E. Glasgow, P. Arean, D. Hessler, Predicting diabetes distress in patients with type 2 diabetes: a longitudinal study, Diabet. Med. 26 (6) (2009) 622-627.

[7] L. Fisher, D.M. Hessler, W.H. Polonsky, J. Mullan, When is diabetes distress clinically meaningful? Diabetes Care 35 (2) (2012) 259-264.

[8] A. Schmitt, A. Reimer, B. Kulzer, T. Haak, D. Ehrmann, N. Hermanns, How to assess diabetes distress: comparison of the problem areas in diabetes scale (PAID) and the diabetes distress scale (DDS), Diabet. Med. 33 (6) (2016) 835 843.

[9] J. Wardian, F. Sun, Factors associated with diabetes-related distress: implications for diabetes self-management, Soc. Work Health Care 53 (4) (2014) 364-381.

[10] D. Hessler, L. Fisher, W. Polonsky, N. Johnson, Understanding the areas and correlates of diabetes-related distress in parents of teens with type 1 diabetes, J. Pediatr. Psychol. 41 (7) (2016) 750-758.

[11] E.K. Fenwick, G. Rees, E. Holmes-Truscott, J.L. Browne, F. Pouwer, J. Speight What is the best measure for assessing diabetes distress? A comparison of the Problem Areas in Diabetes and Diabetes Distress Scale: results from Diabetes MILES-Australia, J. Health Psychol. (2016) 1359105316642006.

[12] L. Fisher, R.E. Glasgow, J.T. Mullan, M.M. Skaff, W.H. Polonsky, Development of a brief diabetes distress screening instrument, Ann. Fam. Med. 6 (3) (2008) 246 252.

[13] M.F. Gray, C. Hsu, L. Kiel, S. Dublin, It's a very big burden on me: women's experiences using insulin for gestational diabetes, Matern. Child Health J. (2017) 1-8.
[14] A. Jones, M.Z. Olsen, H.J. Perrild, I. Willaing, The psychological impact of living with diabetes: descriptive findings from the DAWN2 study in Denmark, Prim. Care Diabetes 10 (1) (2016) 83-86.

[15] E. Holmes-Truscott, T.C. Skinner, F. Pouwer, J. Speight, Negative appraisals of insulin therapy are common among adults with Type 2 diabetes using insulin: results from Diabetes MILES-Australia cross-sectional survey, Diabet. Med. 32 (10) (2015) 1297-1303.

[16] E. Holmes-Truscott, T.C. Skinner, F. Pouwer, J. Speight, Explaining psychological insulin resistance in adults with non-insulin-treated type 2 diabetes: the roles of diabetes distress and current medication concerns. Results from Diabetes MILES-Australia, Prim. Care Diabetes 10 (1) (2016) 75-82.

[17] S. Ramkisson, B. Joseph Pillay, B. Sartorius, Diabetes distress and related factors in South African adults with type 2 diabetes, J. Endocrinol. Metab. Diabetes S. Afr. 21 (2) (2016) 35-39.

[18] W.H. Polonsky, T.R. Hajos, M.P. Dain, FJ. Snoek, Are patients with type 2 diabetes reluctant to start insulin therapy? An examination of the scope and underpinnings of psychological insulin resistance in a large, international population, Curr. Med. Res. Opin. 27 (6) (2011) 1169-1174.

[19] G.R. Slean, E.A. Jacobs, M. Lahiff, L. Fisher, A. Fernandez, Aspects of culturally competent care are associated with less emotional burden among patients with diabetes, Med. Care 50 (2012) S69-S73.

[20] L.E. Joensen, T.P. Almdal, I. Willaing, Associations between patient characteristics, social relations, diabetes management, quality of life, glycaemic control and emotional burden in type 1 diabetes, Prim. Care Diabetes 10 (1) (2016) 41-50.

[21] American Diabetes Association (ADA), Standards of medical care in diabetes2017, Diabetes Care 40 (Suppl. 1) (2017).

[22] M. Benroubi, Fear, guilt feelings and misconceptions: barriers to effective insulin treatment in type 2 diabetes, Diabetes Res. Clin. Pract. 93 (2011) S97 S99.

[23] P. Phillips, Type 2 diabetes-failure, blame and guilt in the adoption of insulin therapy, Rev. Diabet. Stud. 2 (1) (2005) 35.

[24] J. Wardian, Diabetes cannot be controlled, but it can be managed, Clin. Diab. 35 (5) (2017) 329-330.

[25] T.J. Sauerwein, M.W. True, The air force diabetes center of excellence: a model to emulate, Mil. Med. 181 (5) (2016) 407-409.

[26] R.N. Baek, M.A. Tanenbaum, J.S. Gonzalez, Diabetes burden and diabetes distress: the buffering effect of social support? Ann. Behav. Med. 48 (2) (2014) 145-155.

[27] J.L. Strom, L.E. Egede, The impact of social support on outcomes in adult patients with type 2 diabetes: a systematic review? Curr. Diab. Rep. 12 (6) (2012) 769-781.

[28] B.R. Karney, D.S. Loughran, M.S. Pollard, Comparing marital status and divorce status in civilian and military populations, J. Fam. Issues 33 (12) (2012) 15721594.

[29] A. Bushatz, Military Divorce Rate Hits Lowest Level in 10 Years, (2015) Retrieved from http://www.military.com/daily-news/2015/02/25/militarydivorce-rate-hits-lowest-level-in-10-years.html.

[30] L.E. Joensen, Type 1 diabetes and living without a partner: psychological and social aspects, self-management behaviour, and glycaemic control, Diabetes Res. Clin. Pract. 101 (3) (2013) 278-285. 